\title{
PROOF OF A DOUBLE INEQUALITY IN TRIANGLES
}

\author{
JIAN LIU
}

Abstract. A double geometric inequality involving the side lengths, medians, angle bisectors and exradius of a triangle is proved by applying the " $R-r-s$ " method in the theory of triangle inequalities. Several corollaries are obtained by using the main result and the other known inequalities.

Mathematics subject classification (2020): 51M16.

Keywords and phrases: Triangle, Euler's inequality, Gerretsen's inequality, Sondat's inequality, Ciamber-lini's inequality, Walker's inequality.

\section{REFERENCES}

[1] O. Bottema, R. Z. Djordjević, R. R. Janić, D. S. Mitrinovicć, P. M. Vasić, Geometic Ineqalities, Wolters-Noordhoff: Groningen, The Netherlands, 1969.

[2] O. Bottema, Inequalities for $R, r$ and $s$, Univ. Begrad. Publ. Elektrotehn. Fak. Ser. Mat. Fiz, 338352, 1971, 27-36.

[3] C. Ciamberlini, Sulla condizione necessaria esufficiente affinche un trian goto sia acutangolo o ottusangolo, Bull. Un. Mat. Ita, 5, 2 (1943), 37-41.

[4] X.-G. CHU AND X.-Z. YANG, On some inequalities involving the medians of a triangle, Inequality study (edited by X.-Z Yang), Lhasa: The Tibet people's Publishing House, 2000.

[5] X.-G. Chu And J. LiU, Generalization of a geometric inequality, Missouri Journal of Mathematical Sciences, 21, 3 (2009), 155-162.

[6] T. O. Dao, T. D. NGuYen And N. M. Pham, A strengthened version of the Erdös-Mordell inequality, Forum Geom, 16 (2016), 317-321.

[7] W.-D. JiAng AND M. BENCZE, Some geometric inequalities involving angle bisectors and medians of a triangle, J. Math. Inequal, 5, 3 (2011), 363-369.

[8] J. LiU, Some new inequalities for triangles, Middle school mathematics monthly (Jiangsu), 5 (1994), 9-12, (in Chinese).

[9] J. LiU, X.-G., CHU, A new geometric inequality with the Fermat problem, Journal of East China Jiaotong University, 20, 1 (2003), 89-93, (in Chinese).

[10] J. LIU, On a sharp inequality for the medians of a triangle, Transylvanian Journal of Mathematics and Mechanics, 2, (2) 2010, 141-148.

[11] J. LIU, On an inequality for the medians of a triangle, Journal of Science and Arts, 2 (19)-(2012), 127-136.

[12] J. LIU, Sharpened versions of the Erdös-Mordell inequality, J. Inequal. Appl, 2015: 206 (2015), 12. pp.

[13] J. LIU, Refinements of the Erdös-Mordell inequality, Barrow's inequality, and Oppenheim's inequality, J. Inequal. Appl, 2016: 9 (2016), 18. pp.

[14] J. LiU, New refinements of the Erdös-Mordell inequality, J. Math. Inequal, 12, 1 (2018), 63-75.

[15] J. LiU, New Refinements of the Erdös-Mordell Inequality and Barrow's Inequality, Mathematics, 7 (8), (2019), Article ID 276, 12. pp.

[16] J. LIU, An improved result of a weighted trigonometric inequality in acute triangles with applications, J. Math. Inequal, 14, 1 (2020), 147-160.

[17] J. LIU, Three sine inequality, Harbin: Harbin institute of technology press, 2018.

[18] J. LIU, Further generalization of Walker's inequality in acute triangles and its applications, Aims Math, 5 (6)-(2020), 6657-6672. 
[19] D. S. Mitrinović, J. E. PeČArić And V. Volenec, Recent Advances in Geometric Inequalities, Dordrecht-Boston-London: Kluwer Academic Publishers, 1989.

[20] D. S. MARINESCU AND M. MoneA, About a strengthened version of the Erdös-Mordell inequality, Forum Geom, 17 (2017), 197-202.

[21] A. W. Walker, Problem E2388, Amer. Math. Monthly, 1135, (1972), 79.

[22] Y.-D. WU, Z.-H. Zhang AND C.-L. LiAng, Some geometric inequalities relating to an interior point in triangle, International Journal of Mathematical Education in Science and Technology, 41, 5(2010), 677-687.

[23] S.-H. Wu AND M. Bencze, An equivalent form of the fundamental triangle triangle inequality and its applications, J. Inequal. Pure Appl. Math., 10, (1) (2009), Article 16.

[24] S.-H. WU AND Y.-M. CHU, Geometric interpretation of Blundon's inequality and Ciamberlini's inequality, J. Inequal. Appl, 2014: 381 (2014), 18. pp. 